Article

\title{
Surface Properties and Denitrification Performance of Impurity-Removed Rare Earth Concentrate
}

\author{
Kai Zhang ${ }^{1}$, Yuze Bai ${ }^{1}$, Zhijun Gong ${ }^{1,2}$, Zengwu Zhao ${ }^{2}$, Baowei $\mathrm{Li}^{1}$ and Wenfei $\mathrm{Wu}^{1,2, *}$ \\ 1 College of Environment and Energy, Inner Mongolia University of Science and Technology, Baotou 014000, \\ Inner Mongolia, China; btzk@imust.cn (K.Z.); byz1107@163.com (Y.B.); Gong@imust.cn (Z.G.); \\ lbw@imust.cn (B.L.) \\ 2 Key Lab Laboratory of Integrated Exploitation of Bayan Obo Multi-Metal Resources, Baotou 014000, \\ Inner Mongolia, China; zze@imust.cn \\ * Correspondence: wwf@imust.cn; Tel./Fax: +86-04725951567
}

Received: 22 December 2019; Accepted: 21 January 2020; Published: 26 January 2020

check for updates

\begin{abstract}
Acid leaching and alkali roasting were used to remove impurities such as $\mathrm{Ca}$ and $\mathrm{Si}$ in Baiyun Obo rare earth concentrate. The effects of acid-base treatment on the physical and chemical properties of the samples were analyzed by scanning electron microscopy, X-ray diffraction, Brunauer-Emmett-Teller characterization, $\mathrm{X}$-ray photoelectron spectroscopy, $\mathrm{H}_{2}$-temperature-programmed reduction, $\mathrm{NH}_{3}$-temperature-programmed desorption (TPD), and NO-TPD. Results showed that the content of $\mathrm{Ce}_{7} \mathrm{O}_{12}$ in the rare earth concentrates increased and the dispersion was uniform. The grains became smaller, the specific surface area of rare earth concentrates increased, and the active sites were more exposed. Ce coexisted in the form of $\mathrm{Ce}^{3+}$ and $\mathrm{Ce}^{4+}$, whereas $\mathrm{Fe}$ coexisted in the form of $\mathrm{Fe}^{3+}$ and $\mathrm{Fe}^{2+}$. The content of $\mathrm{Fe}^{3+}$ was increased. The acid-base-treated rare earth concentrates had a denitration efficiency of $87.4 \%$ at a reaction temperature of $400{ }^{\circ} \mathrm{C}$.
\end{abstract}

Keywords: rare earth concentrate; active powder; structure-activity relationship; $\mathrm{NH}_{3}-\mathrm{SCR}$; catalytic activity

\section{Introduction}

Rare earth-doped oxides are the main active constituents of catalysts for selective catalytic reduction with $\mathrm{NH}_{3}\left(\mathrm{NH}_{3}-\mathrm{SCR}\right)$. The low-temperature activity and antitoxicity of rare earth element-doped transition metal elements are hot topics in the research field of novel SCR catalysts [1-3]. The rare earth concentrate contains large amounts of elements such as $\mathrm{Ce}, \mathrm{Fe}, \mathrm{Mn}$, etc. Rare earth element and transition metal element-doped oxide can improve low-temperature SCR catalytic activity and its sulfur resistance. The catalytic activity and sulfur resistance of the catalyst are improved because of the abundant active sites on the surface and the coexistence of elements such as Fe and Ce in different valence states. The catalyst can increase the active sites and oxygen storage capacity and promote the reaction of gases such as $\mathrm{NH}_{3}$ and $\mathrm{NO}_{\mathbf{X}}$ [4-6].

Natural minerals are used to improve the catalytic performance of minerals via physical and chemical methods; they are utilized as catalysts instead of those prepared by doping different elements synthesized using purified chemicals [7]. For example, the $\mathrm{V}_{2} \mathrm{O}_{5}-\mathrm{WO}_{3}\left(\mathrm{MoO}_{3}\right) / \mathrm{TiO}_{2}$ catalyst prepared by using pure substances has a poor treatment effect on exhausted flue gas under low-temperature conditions [8-10]. According to the results of previous studies, the short plates of purely prepared catalysts are gradually being exposed. Therefore, developing new green and highly efficient catalysts by loading transition metal elements with natural minerals has become a topic of interest.

The Baiyun Obo fluorocarbon antimony ore has many complex mineral phases. The elements are fine and heterogeneous, and their natural mineral phases are complex and variable. In preparing 
catalysts using pure substances, various mineral phase structures coexist, and a plurality of elements cooperate to improve the catalytic activity of the catalyst [11,12]. In this study, we retained the natural mineral phase and modified and optimized the natural mineral phase structure to enhance the catalytic activity of natural minerals. In preparing the catalyst, the purified substances in the natural minerals do not need to be extracted. This avoids the complicated extraction process, and the catalyst ore phase prepared by using natural minerals is relatively stable compared with the catalyst synthesized using pure substances. A suitable liquid phase system was designed to dissolve it. The mineral phase, which favors the catalytic reaction, was exposed on the surface of the mineral, and a pore structure formed by dissolution and calcination was established on the surface of the mineral [13-16]. By re-integrating rare earth and transition elements, a solid solution, which is favorable for catalysis, was formed and was more exposed to the surface of the pores, thereby enhancing the dispersibility and acidic sites of the surface active components. The adsorption characteristics lowered the activation energy of the denitration reaction and the reaction temperature window of the catalyst prepared by the rare earth concentrate, thereby improving the catalytic activity of the catalyst [17-19]. These findings will have important theoretical significance and practical value in the research and development of new low-temperature SCR catalysts and play a promising role in the application of Baiyun Obo rare earth concentrates to industrial production.

\section{Experimental}

\subsection{Materials}

The main raw materials used in this experiment were 300-400-mesh rare earth concentrate powders produced from the No. 2 mine mouth of Baotou Baiyun Obo Mining Area (Baotou, China). Other reagents were of analytical grade.

\subsection{Analysis and Testing Equipment}

The test equipment included an X-ray diffractometer (PANalytical B.V., Amsterdam, Holland), a Sigma-500 field emission scanning electron microscope (Zeiss, Oberkochen, Germany), a STA449C thermal analyzer (Netzsch, Selb, Germany), a 3H-2000PS1 automated specific surface and aperture analyzer (BeiShiDe Instruments, Beijing, China), a PCA-1200 temperature-programmed chemical adsorption instrument (Builder, Beijing, China), a VERTEX70 Fourier in situ infrared spectrometer (Bruker, Billerica, MA, USA), an X-ray fluorescence analysis device (U-2200 RoHS Heavy Metal Detection Spectrometer), and a Thermo ESCALAB 250Xi X-ray photoelectron spectrometer (Thermo Fisher Scientific, Shanghai, China).

\subsection{Sample Preparation}

At a 300-400-mesh particle size, a certain amount of rare earth concentrates was crushed, ground, sieved, and dried.

a. Sample 1:

The rare earth concentrate raw ore was placed in an oven at $80^{\circ} \mathrm{C}$ for drying, and after the water evaporated, the mineral on the filter paper was collected to obtain the raw ore material.

b. Sample 2:

We measured $10 \mathrm{~mol} / \mathrm{L}$ acetic acid into a beaker, then weighed $5 \mathrm{~g}$ minerals, stirring at room temperature under the action of a magnetic stirrer to form a uniform suspension. Next we added the mixed material to a centrifuge tube for shaking for $2 \mathrm{~h}$, then let it stand. After $24 \mathrm{~h}$, the sample was washed with water, filtered, and finally the sample was dried in an oven at $80{ }^{\circ} \mathrm{C}$. After the water evaporated, the minerals on the filter paper were collected to obtain an acetic acid-treated material.

c. Sample 3:

We measured $2 \mathrm{~mol} / \mathrm{L} \mathrm{HF}$ acid and placed it in a beaker, then weighed $5 \mathrm{~g}$ minerals, stirring at room temperature under the action of a magnetic stirrer to form a uniform suspension. Next we added 
the mixed material to a centrifuge tube for shaking for $2 \mathrm{~h}$, then let it stand. After $48 \mathrm{~h}$, the sample was washed with water, filtered, and placed in an oven at $80^{\circ} \mathrm{C}$ to dry. After the water evaporated, we collected the minerals on the filter paper to obtain the HF acid treatment material.

d. Sample 4:

We weighed out $1.2 \mathrm{~g} \mathrm{Na}_{2} \mathrm{CO}_{3}$ and $0.4 \mathrm{~g} \mathrm{NaOH}$ in a mortar, then weighed $5 \mathrm{~g}$ minerals, ground in a mortar to form a uniform solid, added the uniformly mixed materials to the crucible, and roasted them at $500{ }^{\circ} \mathrm{C}$ for $2 \mathrm{~h}$. The sample was then washed with deionized water, filtered, and placed in an oven at $80{ }^{\circ} \mathrm{C}$ to dry. After the water evaporated, the minerals on the filter paper were collected to obtain an alkali-treated material.

e. Sample 5:

We repeated steps $\mathrm{b} \rightarrow \mathrm{c} \rightarrow \mathrm{d}$.

\subsection{Catalyst Activity Test Method}

The experimental instruments included a quartz tube, riser furnace, sampler, Fourier infrared spectrum flue gas analyzer, and computer data acquisition system. The riser furnace with a rated temperature of $1600{ }^{\circ} \mathrm{C}$ was produced by Nanjing Boyuntong Instrument Technology (Nanjing, China). A 1800 model silicon molybdenum rod with an inner diameter of $20 \mathrm{~mm}$ and a length of $1.2 \mathrm{~m}$ was heated. The FIS gas analyzer (GASMET-DX4000 model, Wuhan, China) and data acquisition system (GASMET-DX4000 model, Wuhan, China) were used for online measurement of smoke components. A reaction bed was used to support the catalyst. The experimental principle of its activity is:

$$
\begin{gathered}
4 \mathrm{NO}+4 \mathrm{NH}_{3}+\mathrm{O}_{2}=4 \mathrm{~N}_{2}+6 \mathrm{H}_{2} \mathrm{O} \\
2 \mathrm{NO}_{2}+4 \mathrm{NH}_{3}+\mathrm{O}_{2}=3 \mathrm{~N}_{2}+6 \mathrm{H}_{2} \mathrm{O} \\
6 \mathrm{NO}+4 \mathrm{NH}_{3}=5 \mathrm{~N}_{2}+6 \mathrm{H}_{2} \mathrm{O} \\
6 \mathrm{NO}_{2}+8 \mathrm{NH}_{3}=7 \mathrm{~N}_{2}+12 \mathrm{H}_{2} \mathrm{O} .
\end{gathered}
$$

Approximately $1 \mathrm{~g}$ of sample and $0.5 \mathrm{~g}$ quartz wool were weighed in the heating section of the quartz tube, which is equivalent to the reaction bed used to support the catalyst. Before the start of the experiment, the vertical tube furnace was heated from room temperature to the experimental temperature at a rate of $10{ }^{\circ} \mathrm{C} / \mathrm{min}$. The composition of the simulated flue gas was $0.05 \% \mathrm{NH}_{3}, 0.05 \%$ $\mathrm{NO}, 3 \% \mathrm{O}_{2} ; \mathrm{N}_{2}$ was the equilibrium gas, and the space velocity was about $6000 \mathrm{~h}^{-1}$. The flow rate of the simulated flue gas was $0.1 \mathrm{~L} / \mathrm{min}$. The reaction gas was passed through for $30 \mathrm{~min}$ and monitored with a flue gas analyzer. After the test temperature and gas concentration were stable, the test was performed quickly. The sample was poured into a quartz tube with a constant temperature zone, and the catalyst denitration efficiency was calculated using a Fourier infrared spectrum flue gas analyzer and a computer acquisition data system.

$$
\eta=\frac{(N O)_{\text {in }}-(N O)_{\text {out }}}{(N O)_{\text {out }}} \times 100 \%,
$$

where $\eta$ is the $\mathrm{NO}$ removal rate, $(\mathrm{NO})_{\text {in }}$ is the percentage of flue gas detected at the inlet of the $\mathrm{NO}$, and $(\mathrm{NO})_{\text {out }}$ is the percentage of flue gas detected at the outlet of the NO. 


\section{Results and Discussion}

\subsection{Morphological Characterization}

\subsubsection{Scanning Electron Microscopy (SEM) Characterization}

The effect of each treatment on the surface morphology of each active powder was observed by SEM. The changes of the surface morphology of the active powder, including the distribution of elements and the change of mineral phase, were analyzed.

As shown in the SEM image, the mineral material underwent different changes on the surface of the rare earth concentrate after different treatments. After treatment with acetic acid (Figure 1c) and hydrofluoric acid (Figure $1 \mathrm{~b}$ ), $\mathrm{CaCO}_{3}, \mathrm{Ca}(\mathrm{OH})_{2}$, and $\mathrm{SiO}_{2}$ dissolved, causing the surface of the mineral material to change from smooth to rough. After hydrofluoric acid treatment (Figure 1b), the surface of the sample became rough, and some minerals fell off to form finely divided particles. The surface showed obvious signs of acid erosion, indicating that hydrofluoric acid (Figure 1b) impregnation can improve the mineral surface area. The surface of the sample treated with acetic acid (Figure 1c) was rough, and some mineral particles were interlaced with stick-like minerals on the surface, forming a network structure, which greatly increased the surface area of the mineral. The minerals calcined by alkali (Figure 1d) had a rough interface, in which the mineral particles were partially cracked because some of the mineral phases decomposed during the calcination process, causing cracks on the surface of the minerals. The surface of the mineral calcined by acid-base (Figure 1e) was rough, and part of the crack occurred at the same time. The surface of the particles formed a flocculent package, which was converted from large to small granular minerals. In addition, the specific surface area and active sites increased. In terms of the surface morphology of the mineral material, the sample treated with acid and alkali had a larger specific surface area relative to the original ore, facilitating the adsorption and desorption of the reaction gas on the mineral surface and providing a sufficient reaction site for the occurrence of the catalytic experiment. This promoted the improvement of the denitration efficiency of the catalyst.

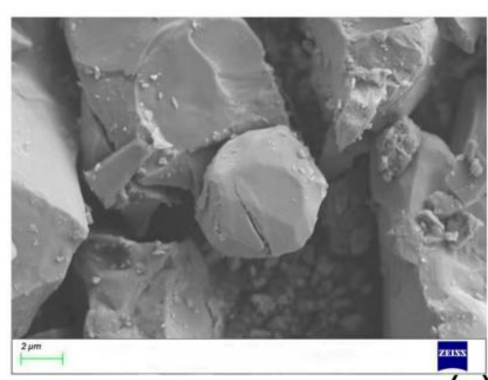

(a)

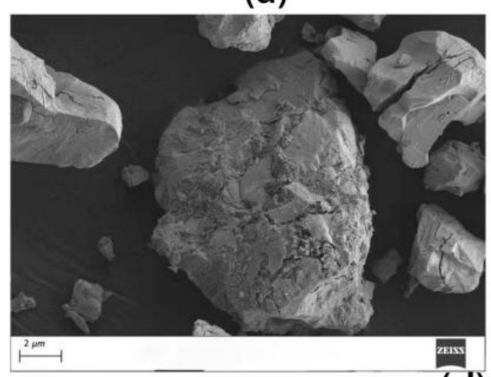

(d)

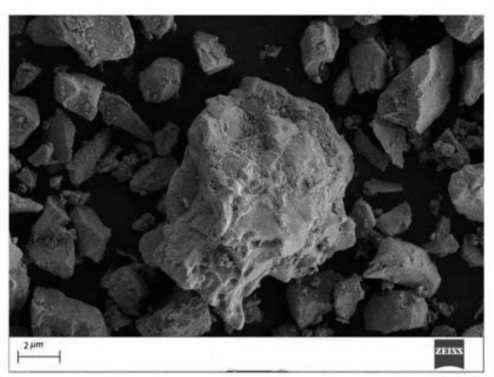

(b)

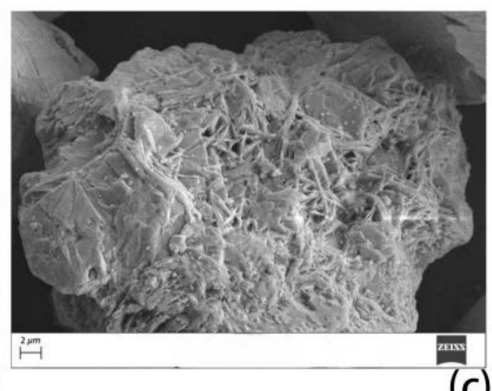

(c)

Figure 1. SEM characterization of rare earth concentrates subjected to different treatments. (a) Sample 1, (b) Sample 2, (c) Sample 3, (d) Sample 4, (e) Sample 5. 


\subsubsection{Analysis of Element Types and Contents}

The composition of elements in the active powder after acid and alkali treatment changed simultaneously, including the elements eluted by acid leaching and those washed out by the alkali roasting process (ass $\%=$ Element content/Total element content). In order to keep the metal elements and nonmetal elements consistent, we converted metal oxides into elemental forms.

As seen from the Table 1, phosphate, calcium salt, iron salt, bastnäsite, and a small amount of $\mathrm{SiO}_{2}$ were present in the ore. The calcium salt in the naturally occurring mineral material was dissolved with acetic acid, forming acid sites on the surface of the material. The calcium content of the acetic acid-treated active powder decreased by $15 \%$. Natural minerals contain a small amount of $\mathrm{SiO}_{2}$. Hydrofluoric acid was added primarily to create a large specific surface area on the surface of the mineral. The introduction of hydrofluoric acid will increase the content of F. Alkali calcination decomposed the bastnäsite in the ore and removed $\mathrm{F}$ by converting it into NaF. The relative content of the active component effectively increased during treatment, thereby facilitating the occurrence of the catalytic reaction.

Table 1. XRF characterization of rare earth concentrates.

\begin{tabular}{|c|c|c|c|c|c|}
\hline \multirow[t]{2}{*}{ Element } & Sample $1(\%)$ & \multirow[t]{2}{*}{ Sample $2(\%)$} & \multirow[t]{2}{*}{ Sample $3(\%)$} & \multirow[t]{2}{*}{ Sample $4(\%)$} & \multirow[t]{2}{*}{ Sample $5(\%)$} \\
\hline & (Raw Ore) & & & & \\
\hline $\mathrm{F}$ & 6 & 5 & 6 & 3 & 3 \\
\hline $\mathrm{Na}$ & $\leq 1$ & 1 & $\leq 1$ & $\leq 1$ & $\leq 1$ \\
\hline $\mathrm{Mg}$ & $\leq 1$ & $\leq 1$ & $\leq 1$ & $\leq 1$ & 0.4 \\
\hline $\mathrm{Al}$ & $\leq 1$ & $\leq 1$ & $\leq 1$ & $\leq 1$ & $\leq 1$ \\
\hline $\mathrm{Si}$ & 3 & 2 & 1 & 2 & $\leq 1$ \\
\hline $\mathrm{P}$ & 12 & 7 & 3 & 10 & 1 \\
\hline$S$ & 5 & 5 & 3 & 4 & 1.1 \\
\hline $\mathrm{K}$ & $\leq 1$ & $\leq 1$ & $\leq 1$ & $\leq 1$ & $\leq 1$ \\
\hline $\mathrm{Ca}$ & 20 & 8 & 15 & 19 & 4 \\
\hline $\mathrm{Ti}$ & $\leq 1$ & $\leq 1$ & $\leq 1$ & $\leq 1$ & $\leq 1$ \\
\hline $\mathrm{Fe}$ & 11 & 10 & 10 & 8 & 12 \\
\hline $\mathrm{Zn}$ & 2 & $\leq 1$ & $\leq 1$ & $\leq 1$ & $\leq 1$ \\
\hline $\mathrm{Sr}$ & $\leq 1$ & $\leq 1$ & $\leq 1$ & $\leq 1$ & $\leq 1$ \\
\hline $\mathrm{Nb}$ & $\leq 1$ & $\leq 1$ & $\leq 1$ & $\leq 1$ & $\leq 1$ \\
\hline $\mathrm{Ba}$ & $\leq 1$ & $\leq 1$ & $\leq 1$ & $\leq 1$ & $\leq 1$ \\
\hline $\mathrm{La}$ & 10 & 9 & 13 & 12 & 18 \\
\hline $\mathrm{Ce}$ & 16 & 33 & 32 & 29 & 40 \\
\hline $\operatorname{Pr}$ & 3 & 5 & 5 & 4 & 8 \\
\hline $\mathrm{Nd}$ & 9 & 8 & 5 & 5 & 7 \\
\hline $\mathrm{Pb}$ & 2 & 6 & 5 & 2 & 3 \\
\hline $\mathrm{Mn}$ & $\leq 1$ & $\leq 1$ & $\leq 1$ & $\leq 1$ & 1 \\
\hline $\mathrm{Pd}$ & $\leq 1$ & $\leq 1$ & $\leq 1$ & $\leq 1$ & $\leq 1$ \\
\hline Th & $\leq 1$ & $\leq 1$ & $\leq 1$ & $\leq 1$ & $\leq 1$ \\
\hline
\end{tabular}

\subsubsection{Brunauer-Emmett-Teller (BET) Characterization}

As seen from the Table 2, the specific surface area of rare earth concentrates will increase after different treatments. Alkali roasting also increases the specific surface area mainly due to the decomposition of minerals and the formation of cracks. The reason why acid treatment increases the specific surface area is that the surface is eroded and voids and depressions are formed on the surface. The acid-base-treated sample was calcined by alkali on the basis of acid-base erosion. Erosion formed on the surface, and the mineral was decomposed, forming cracks. Thus, many active components were exposed on the mineral surface. Combined with X-ray diffraction to reach a conclusion after the rare earth concentrate was treated, the specific surface area increased to $17.1 \mathrm{~m}^{2} / \mathrm{g}$, exposing active substances in minerals to the surface of minerals. This will facilitate the full contact of the reaction 
gas with the surface adsorption site of the catalyst, increase the adsorption amount, and promote the SCR reaction. The pore volume was increased to $1.2(\mathrm{~mL} / \mathrm{g})$, and the average pore size was reduced, forming a larger pore volume and a richer mesoporous structure. This provides more active adsorption sites for the reaction gas and facilitates the desorption and discharge of reaction products in the pores, thereby facilitating the SCR reaction.

Table 2. BET characterization of rare earth concentrates under different conditions.

\begin{tabular}{ccc}
\hline & Specific Surface Area $\left(\mathbf{m}^{2} / \mathbf{g}\right)$ & Average Aperture $(\mathbf{n m})$ \\
\hline Sample1 & 0.7 & 1.24 \\
Sample2 & 7.8 & 6.86 \\
Sample4 & 8.3 & 1.15 \\
Sample3 & 8.5 & 2.98 \\
Sample5 & 17.1 & 1.19 \\
\hline
\end{tabular}

\subsection{Structural Characterization}

\subsubsection{Thermogravimetric Analysis of Rare Earth Concentrates}

Although the Baotou rare earth concentrate has a high rare earth content, it has more non-rare earth impurities and more complex components. To better explore the mineral phase changes of rare earth concentrates at high temperatures, a thermogravimetric analysis was conducted.

The rare earth concentrate was dried at $110{ }^{\circ} \mathrm{C}$ before the experiment to eliminate moisture. The sample was pretreated before the Thermogravimetric Analysis-Differential Scanning Calorimetry test, and the gas adsorbed by the rare earth concentrate was substantially desorbed. Before $350{ }^{\circ} \mathrm{C}$, no significant change was observed in the TG curve, indicating that the rare earth concentrate had no weight loss and was in an exothermic state at this temperature. In the temperature range of $350-500{ }^{\circ} \mathrm{C}$, $7 \%$ weight loss and a large peak were observed. The weight loss was due to the decomposition of $\mathrm{CO}_{2}$ by $\mathrm{REFCO}_{3}$ during roasting. The TG curve at $500-530{ }^{\circ} \mathrm{C}$ did not show weight loss, but a large endothermic peak appeared, which was caused by further oxidation of the mineral $\mathrm{CeOF}$ to $\mathrm{Ce}_{7} \mathrm{O}_{12}$. The weight loss of the TG curve at $530-650^{\circ} \mathrm{C}$ is due to the conversion of $\mathrm{Ce}_{7} \mathrm{O}_{12}$ to $\mathrm{CeO}_{2}$ in the rare earth concentrate. Significant weight loss occurred in the temperature range of $650-1000{ }^{\circ} \mathrm{C}$, and a broad endothermic peak appeared. This was due to the calcination of carbonates, and some components were sintered in rare earth concentrates. Through the TG-DSC curve, the changes of the ore phase of rare earth concentrates at different temperature ranges were observed. Fluorocarbon lanthanum was the dominant ore phase in the rare earth concentrate at different calcination temperature sections, thus providing theoretical support for the roasting test.

\subsubsection{X-Ray Diffraction Analysis}

The Ce content in minerals treated with different concentrations of acetic acid and hydrofluoric acid did not decrease; however, the crystallinity and dispersion of minerals changed remarkably. The samples with better catalytic activity were tested as shown in Figure 2.

As shown in the figure, acetic acid and hydrofluoric acid treatment did not lead to a new mineral phase compared with the original ore. In addition, the original ore phase did not disappear; however, the diffraction peak of some mineral phases became sharper. This finding indicated that, during the acid impregnation process, the crystal structure of the ore changed, and the Ce that was encapsulated and embedded in the mineral was exposed to the surface of the mineral, increasing the crystallinity of the crystal. Acetic acid and hydrofluoric acid impregnation effectively increased the content of rare earth compounds on the surface of rare earth concentrates, whereas acid erosion increased the specific surface area of rare earth concentrates, providing more acid sites for gases in the catalytic process and improving the catalytic performance of the active powder. 


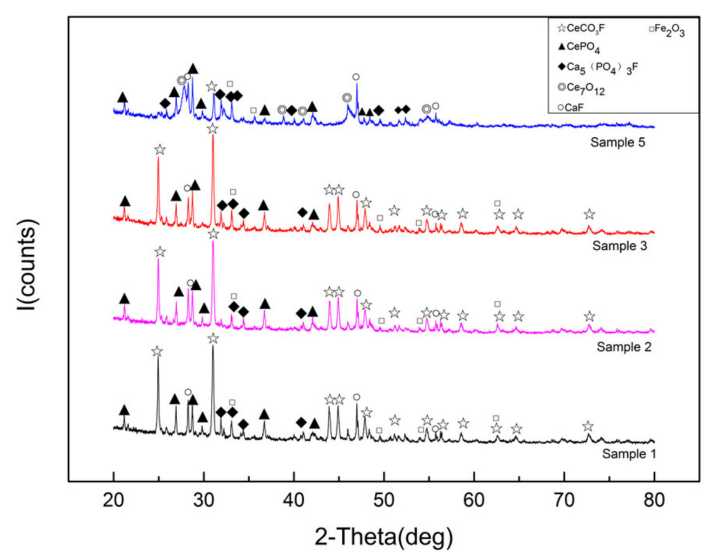

Figure 2. Analysis of rare earth concentrate ore phase subjected to different treatments.

The difference between the diffraction peaks of the active powder calcined at $500{ }^{\circ} \mathrm{C}$ and the original ore after co-treatment with acetic acid, hydrofluoric acid, and alkali treatment was great. Compared with $\mathrm{CePO}_{4}$ and $\mathrm{Ca}\left(\mathrm{PO}_{4}\right)_{3} \mathrm{~F}$ in the ore phase, the treated active powder partially decomposed rare earth elements while retaining the original ore phase and forming $\mathrm{Ce}_{7} \mathrm{O}_{12}$ and transition metal oxide (such as $\mathrm{Fe}_{2} \mathrm{O}_{3}$ ). This caused the rare earth element and the transition metal element to form a composite oxide and promoted the catalytic reaction efficiency of the active powder. The co-treatment of acetic acid and hydrofluoric acid not only improved the defluorination efficiency, but also reduced impurities while increasing the $\mathrm{CeO}_{2}$ content and optimizing the dispersion of $\mathrm{CeO}_{2}$, thereby effectively improving the activity of the catalyst.

\subsubsection{X-Ray Photoelectron Spectroscopy (XPS) Analysis}

According to reports in the literature, there are two forms of Ce present in minerals. As shown in the Figure 3, one is $\mathrm{Ce}^{3+}: \mathrm{u}_{0}(\mathrm{BE} \approx 884.4 \mathrm{eV})$ and $\mathrm{u}_{0}{ }^{\prime}(\mathrm{BE} \approx 903.9 \mathrm{eV})$; the second is $\mathrm{Ce}^{4+}$ : $\mathrm{v}_{0}(\mathrm{BE} \approx 882.2 \mathrm{eV}), \mathrm{v}_{1}(\mathrm{BE} \approx 888.6 \mathrm{eV}), \mathrm{v}_{2}(\mathrm{BE} \approx 898 \mathrm{eV}), \mathrm{V}_{0}{ }^{\prime}(\mathrm{BE} \approx 900.7 \mathrm{eV}), \mathrm{v}_{1}{ }^{\prime}(\mathrm{BE} \approx 907.2 \mathrm{eV})$, and $\mathrm{v}_{2}{ }^{\prime}(\mathrm{BE} \approx 916.15 \mathrm{eV})[20,21]$. Ce in sample 1 was converted from $\mathrm{Ce}^{3+} / \mathrm{Ce}^{4+}+\mathrm{Ce}^{3+}=21.61 \%$ to $\mathrm{Ce}^{3+} / \mathrm{Ce}^{4+}+\mathrm{Ce}^{3+}=61.73 \%$ in sample 5. Therefore, the greater the content of $\mathrm{Ce}^{3+}$, the better the denitration activity of the catalysts in the low-temperature window.

$$
\mathrm{Ce}^{3+}+\mathrm{O}_{2}+\mathrm{v}_{0} \rightarrow \mathrm{Ce}^{4+}+\mathrm{O}_{2}^{-}
$$

The $\mathrm{Ce}^{3+}$ content of the ore was quantitatively analyzed by XPS. The $\mathrm{Ce}^{4+}$ of the acid-base-treated active powder had a new peak in $\mathrm{v}_{1}, \mathrm{v}_{2}$, and $\mathrm{v}_{2}$ ' relative to the original ore, and the corresponding peak areas of $\mathrm{v}_{0}, \mathrm{v}_{0}{ }^{\prime}$, and $\mathrm{v}_{1}{ }^{\prime}$ correspondingly increased. This finding indicated that the content of $\mathrm{Ce}^{4+}$ in the acid-base-treated active powder was increased relative to the ore. The acid-base treatment was beneficial to the conversion of $\mathrm{Ce}^{3+}$ to $\mathrm{Ce}^{4+}$. The valence state of $\mathrm{Ce}$ existed simultaneously with +4 and +3 [22]. This facilitates the storage and release of surface oxygen, thereby increasing surface oxidation and promoting the reduction of nitrogen oxides absorbed on the surface of the active powder.

According to the literature, there are two forms of Fe present in minerals. One is $\mathrm{Fe}^{2+}: \mathrm{h}_{0}$ $(\mathrm{BE} \approx 709.8 \mathrm{eV}), \mathrm{h}_{0}{ }^{\prime}(\mathrm{BE} \approx 722.8 \mathrm{eV}), \mathrm{h}_{1}(\mathrm{BE} \approx 716.4 \mathrm{eV})$, and $\mathrm{h}_{1}{ }^{\prime}(\mathrm{BE} \approx 730.0 \mathrm{eV})$; the second is $\mathrm{Fe}^{3+}$ : $\mathrm{I}_{0}(\mathrm{BE} \approx 711.2 \mathrm{eV}), \mathrm{I}_{0}{ }^{\prime}(\mathrm{BE} \approx 723.4 \mathrm{eV}), \mathrm{I}_{1}(\mathrm{BE} \approx 719.5 \mathrm{eV})$, and $\mathrm{I}_{1}{ }^{\prime}(\mathrm{BE} \approx 733.6 \mathrm{eV})$ [23]. As shown in the figure, $\mathrm{Fe}$ in sample 1 was transformed from $\mathrm{Fe}^{2+} / \mathrm{Fe}^{2+}+\mathrm{Fe}^{3+}=35.17 \%$ to $\mathrm{Fe}^{2+} / \mathrm{Fe}^{2+}+\mathrm{Fe}^{3+}=53.35 \%$ in sample 5 . Therefore, the greater the $\mathrm{Fe}^{2+}$ content, the more the oxygen hole content in the catalyst and the better the low-temperature denitration activity of the catalyst.

$$
\mathrm{Fe}^{2+}+\mathrm{O}_{2}+\mathrm{v}_{0} \rightarrow \mathrm{Fe}^{3+}+\mathrm{O}_{2}^{-}
$$




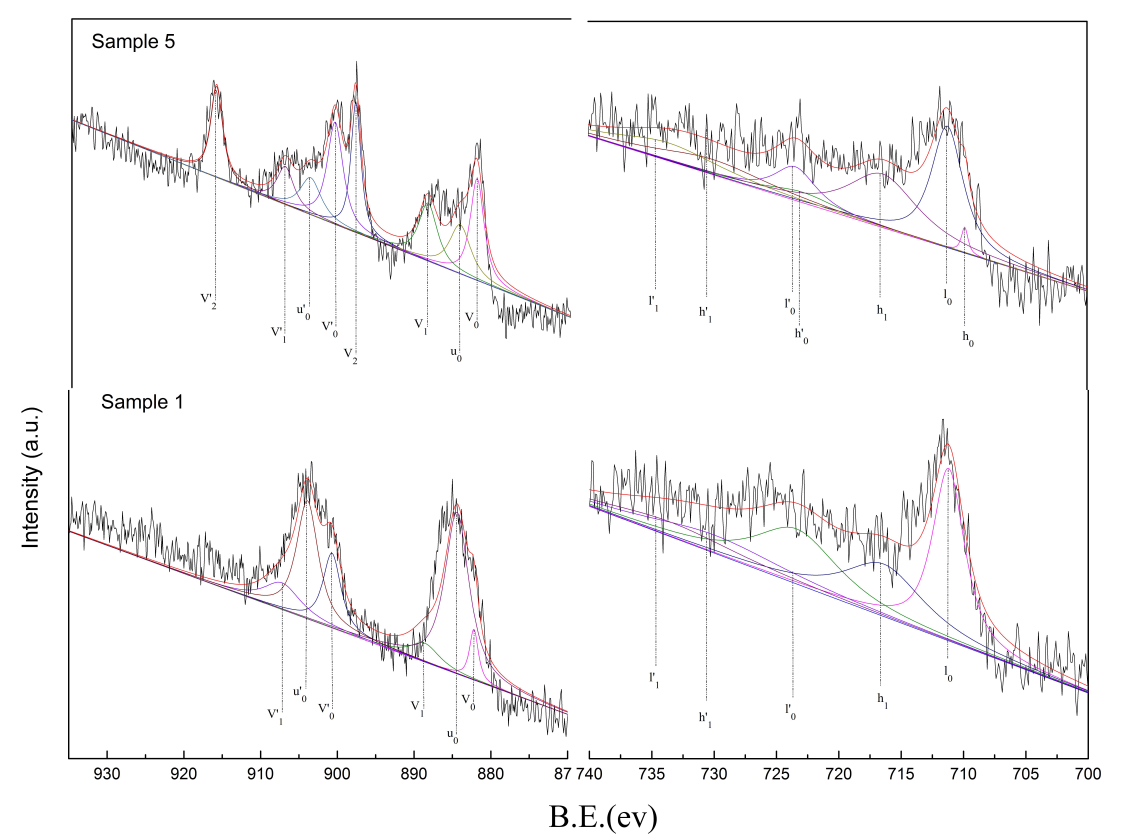

Figure 3. XPS energy spectrum of Ce and Fe 2p orbital on the surface of ore and acid-base co-processed active powder.

According to the semi-quantitative relationship of the fitted peak areas, the active powders subjected to acid-base co-treatment had relatively higher $\mathrm{Fe}^{3+}$ content than the ore. The transition metal element Fe can provide electrons required for the reaction during the SCR reaction, thereby promoting the catalytic reaction of the active powder [24]. The formation of $\mathrm{Fe}^{2+}$ and $\mathrm{Ce}^{3+}$ follows the conservation of charge. When substances with different valence states are formed, oxygen vacancies and adsorption sites are formed on the surface of the mineral catalyst. At the low-temperature stage, $\mathrm{NH}_{3}$ adsorbed on the surface of the mineral catalyst reacts with oxygen adsorbed on the surface to form $\mathrm{NH}_{2}$ and $-\mathrm{OH}$. As the temperature increases, $\mathrm{NH}_{2}$ will react with $\mathrm{NO}$ adsorbed on the surface to form $\mathrm{NH}_{2} \mathrm{NO}$ intermediates. Under certain conditions, $\mathrm{NH}_{2} \mathrm{NO}$ decomposes to form $\mathrm{N}_{2}$ and $\mathrm{H}_{2} \mathrm{O}$. Therefore, the increase of oxygen vacancies and adsorption sites on the catalyst surface through loading has a significant influence on the catalytic efficiency of the catalyst $[25,26]$.

\subsection{4. $\mathrm{H}_{2}$-Temperature-Programmed Reduction $\left(\mathrm{H}_{2}\right.$-TPR) Analysis}

To investigate the ability of metal ions on the surface of modified rare earth concentrates to be reduced to low-valence metal ions and to absorb or release oxygen, an $\mathrm{H}_{2}$-TPR experiment was carried out. The results are shown in Figure 4. 


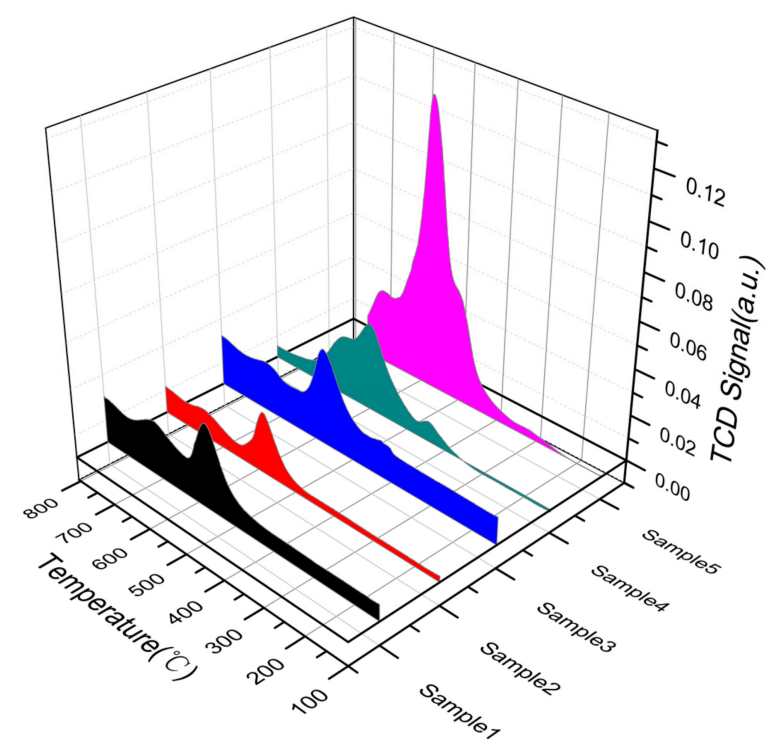

Figure 4. Analysis of the redox capability of rare earth concentrates subjected to different treatments.

As shown in the figure, the rare earth concentrate plus alkali-calcined active powder and the acetic acid-impregnated active powder showed a weak peak at $400{ }^{\circ} \mathrm{C}$. At $500-550{ }^{\circ} \mathrm{C}$, the alkali-calcined active powder, acetic acid-impregnated active powder, hydrofluoric acid-impregnated active powder, and ore showed strong peaks, while the acid-base co-processed active powder was in the range of $500-550{ }^{\circ} \mathrm{C}$. A strong spike and shoulder were present at $750^{\circ} \mathrm{C}$. In addition, a small shoulder appeared in the ore, acetic acid-impregnated active powder, and hydrofluoric acid-impregnated active powder at $600-700{ }^{\circ} \mathrm{C}$. The rare-earth mineral had a de-oxidation peak between $500{ }^{\circ} \mathrm{C}$ and $550{ }^{\circ} \mathrm{C}$. The reason was that $\mathrm{Fe}_{2} \mathrm{O}_{3}$ was converted into $\mathrm{Fe}_{3} \mathrm{O}_{4}$ after being combined with $\mathrm{Ce}$ in rare earth concentrate. Among them, the de-oxidation peak between $500{ }^{\circ} \mathrm{C}$ and $600{ }^{\circ} \mathrm{C}$ corresponded to the conversion process of $\mathrm{Fe}_{3} \mathrm{O}_{4} \rightarrow \mathrm{FeO} \rightarrow \mathrm{Fe}$. The de-oxidation peak between $600{ }^{\circ} \mathrm{C}$ and $750{ }^{\circ} \mathrm{C}$ was attributable to the synergistic effect between $\mathrm{Fe}$ and rare earth concentrate. $\mathrm{Ce}^{4+}$ was converted into $\mathrm{Ce}^{3+}$, namely, $\mathrm{CeO}_{2}$ was converted into $\mathrm{Ce}_{2} \mathrm{O}_{3}$. The alkali-calcined active powder had a broad peak, and its peak area was 547.62. The area of the acid-base co-processed active powder was 641.74 , which was $17.19 \%$ higher than that of alkali treatment [27]. The peak area of the active powder after acid-base co-treatment was greatly improved compared with that of the ore. The active powder prepared by acid leaching and alkali roasting exhibited a good redox ability.

\subsection{5. $\mathrm{NH}_{3}$-Temperature-Programmed Desorption ( $\mathrm{NH}_{3}$-TPD) and NO-TPD Analysis}

To investigate whether the modification treatment affected the surface acidity of the rare earth concentrate, a $\mathrm{NH}_{3}$-TPD experiment was carried out on the rare earth concentrates with different modification treatments. The samples were degassed with Ar gas at $20 \mathrm{~L} / \mathrm{min}$ for $30 \mathrm{~min}$ before running $\mathrm{NH}_{3}-\mathrm{TPD}$ and $\mathrm{H}_{2}$-TPR. The test results are shown in Figure 5.

As shown in the figure, the surface acid amount (from higher to lower) was ordered as follows: acid-base treatment $>$ acetic acid treatment $>$ hydrofluoric acid treatment $>$ additional alkali roasting treatment. Four samples had a weak desorption peak at the low-temperature range $\left(100-250{ }^{\circ} \mathrm{C}\right)$. The peak corresponded to the absorption of $\mathrm{NH}_{3}$ on the weak acid site. A continuous, wide, and strong $\mathrm{NH}_{3}$ desorption peak appeared at the high-temperature range $\left(250-900{ }^{\circ} \mathrm{C}\right)$, which was absorbed by the strong acid site. It was produced after $\mathrm{NH}_{3}$ desorption. This shows that a large number of substances work together to increase the number of acidic sites and surface active sites on the surface of the material, resulting in a large amount of $\mathrm{NH}_{3}$ adsorption on the surface of the material. This finding shows that the surface of particles can be modified to make it rough and porous after the acid-base roasting treatment. 


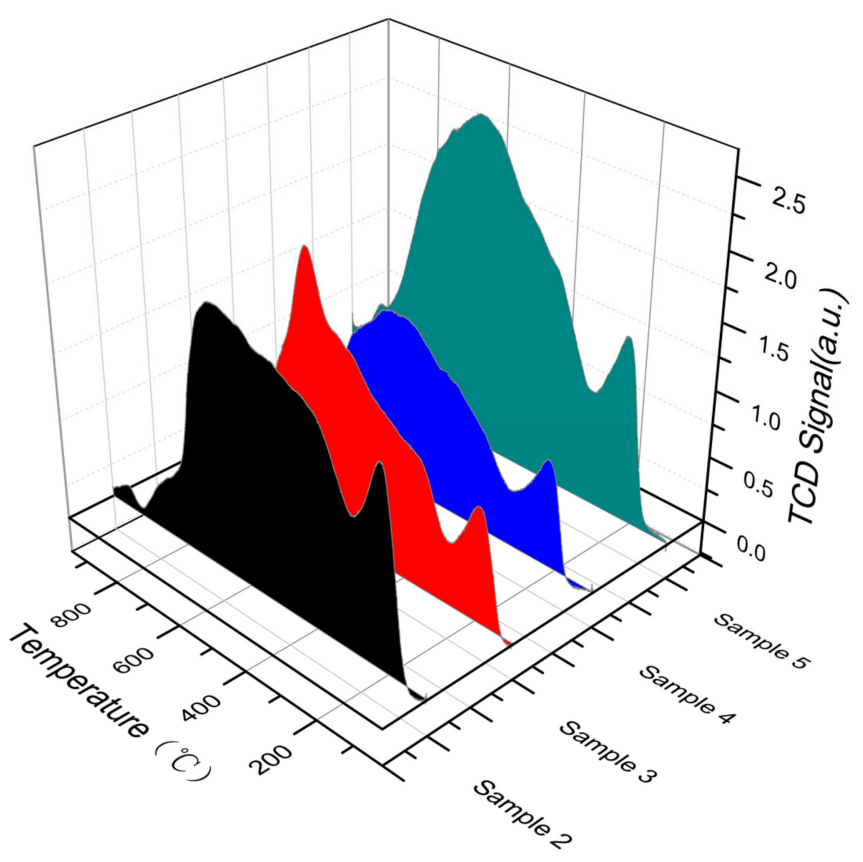

Figure 5. Characterization of $\mathrm{NH}_{3}-\mathrm{TPD}$ in rare earth concentrates subjected to different treatments.

NO can participate in the SCR reaction in the form of adsorption. Therefore, the adsorption capacity of NO can affect the SCR reactivity to some extent. To determine the effect of mineral modification on the adsorption capacity of NO, this paper does NO for the four catalysts. The results of the temperature-programmed adsorption-desorption test are shown in Figure 6.

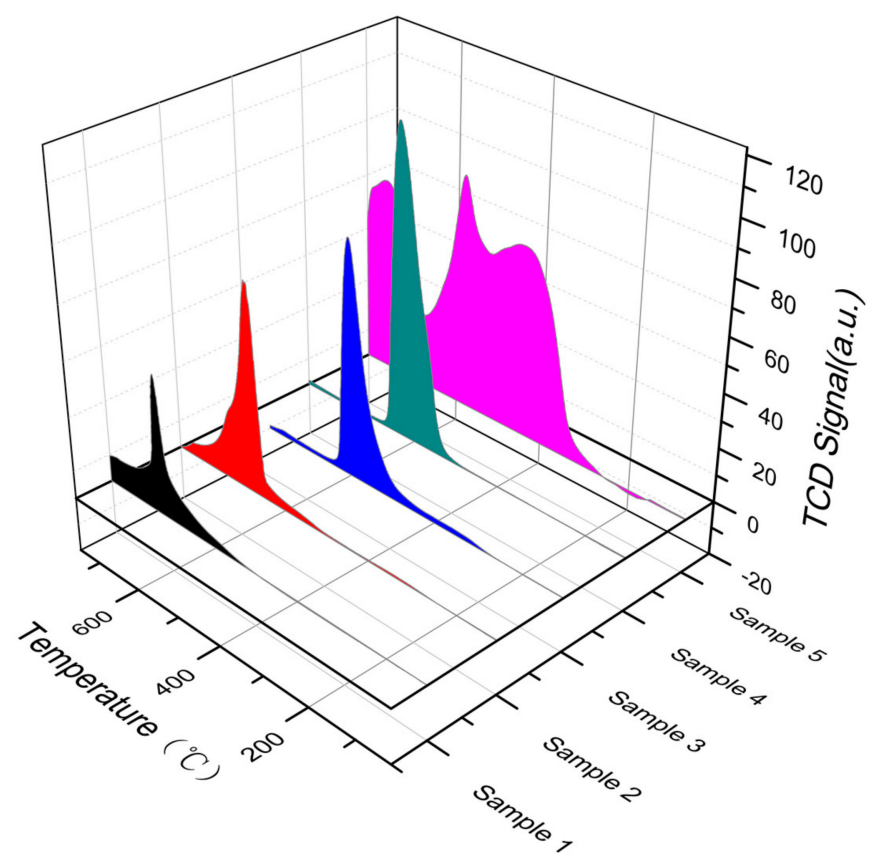

Figure 6. Adsorption characteristics of $\mathrm{NO}$ in samples subjected to different treatment methods.

As shown in the figure, the desorption process of the ore occurred between $400{ }^{\circ} \mathrm{C}$ and $900{ }^{\circ} \mathrm{C}$. The desorption curve after acid treatment occurred at $400-600^{\circ} \mathrm{C}$, and the area of the original ore peak was significantly increased. The desorption curve of the concentrate after alkali treatment was between $600^{\circ} \mathrm{C}$ and $700{ }^{\circ} \mathrm{C}$, and the area of the desorption peak was also significantly increased compared with that of the original ore. The NO adsorption effect of the rare earth concentrate after alkali and acid 
treatment was obviously improved. The NO-TPD peak shape after alkali treatment was stronger than that of the ore, and the desorption peak was enhanced and shifted to the high-temperature direction. The peak value of NO-TPD did not shift significantly after acid treatment; however, the peak width and peak height increased significantly. The acid and alkali treatments had obvious promotion effects on the NO adsorption capacity of rare earth concentrates. This indicates that a large number of substances worked together to absorb NO on the surface of the catalyst, increasing the surface acid amount and surface active sites. The acid-base treatment could modify the surface of the particle to make it rough and porous.

\subsection{SCR Activity of Catalyst}

The NO conversion rate of the samples was measured using a simulated flue gas device. In the best state, the NO conversion rate of the rare earth concentrate powder is only $36.9 \%$. Acetic acid dissolves $\mathrm{CaCO}_{3}$ in the rare earth concentrate and forms a large specific surface area on the surface of the mineral. At the same time, more elements such as $\mathrm{CeFe}$ in the mineral are exposed. The NO conversion efficiency of reached $83.5 \%$ at $350{ }^{\circ} \mathrm{C}$. The $\mathrm{HF}$ acid destroyed $\mathrm{SiO}_{2}$ in the rare earth mineral, collapsed the natural skeleton in the mineral, changed the surface pore structure of the mineral from macropores to micropores, further improved the specific surface area of the rare earth concentrate, and promoted the catalytic efficiency of the material. The NO conversion efficiency of Sample 3 reached $78.9 \%$ at $450{ }^{\circ} \mathrm{C}$. High-temperature roasting of rare earth concentrates and mixed alkalis promoted the conversion of $\mathrm{Ce}, \mathrm{Fe}$, and other substances into oxides and the formation of cracks due to mineral instability under high-temperature conditions. Sample 4: the catalytic activity reached $69.9 \%$ at $450{ }^{\circ} \mathrm{C}$. The specific surface area of the sample treated with acid and alkali was greatly increased; at the same time, oxides of elements such as Ce and Fe formed on the mineral surface, and a layer of highly efficient catalytic material formed on the mineral surface. Sample 5: The catalytic activity reached $91.3 \%$ at $450{ }^{\circ} \mathrm{C}$. The $\mathrm{NO}$ activity reached $87.4 \%$ at $400{ }^{\circ} \mathrm{C}$ because $\mathrm{SiO}_{2}, \mathrm{CaF}$, and other calcium salts were partially dissolved, increasing the specific surface area, which is beneficial to catalytic activity. Calcination caused the effective elements to become exposed on the surface of the mineral material to form a solid solution, thereby improving the catalytic activity.

\section{Conclusions}

The surface of the catalyst was uneven, the specific surface area increased, the average pore diameter decreased, and the pore volume increased. In the active component of the catalyst, Ce coexisted in the forms of $\mathrm{Ce}^{3+}$ and $\mathrm{Ce}^{4+}$, whereas Fe coexisted in the forms of $\mathrm{Fe}^{3+}$ and $\mathrm{Fe}^{2+}$. Moreover, the content of $\mathrm{Fe}^{3+}$ was higher than that of $\mathrm{Fe}^{2+}$. The acid-base co-processed sample decomposed rare earth elements and transition metal elements by retaining the ore phase to form a certain amount of $\mathrm{Ce}_{7} \mathrm{O}_{12}$ and transition metal oxide (such as $\mathrm{Fe}_{2} \mathrm{O}_{3}$ ). Acetic acid dissolved the calcium salt in the naturally occurring mineral material, increasing the specific surface area of the catalyst and forming several acid sites on the surface of the material. In general, the relative content of the active components of the acid-base-treated samples increased, which promoted the conversion of NO, thereby facilitating the SCR reaction. The NO conversion of the sample was measured using a simulated flue gas device. In the best state, the NO conversion rate of the untreated rare earth concentrate powder was only $36.9 \%$. The acid-base-treated rare earth concentrates had a denitration efficiency of $87.4 \%$ at a reaction temperature of $400^{\circ} \mathrm{C}$.

Author Contributions: Conceptualization, K.Z.; Investigation, Y.B.; Project administration, B.L.; Validation, Z.G.; Writing-original draft, Z.Z.; Writing-review \& editing, W.W. All authors have read and agreed to the published version of the manuscript.

Funding: The investigation was financially supported by the National Natural Science Foundation of China (51866013) and by the IMAR (Inner Mongolia Autonomous Region) Natural Science Foundation (2018MS02013, 2018LH05016). The investigation was also financially supported by the Provincial and Ministry of Construction of National Key Laboratory Breeding Base Capacity Building Project (2017-KFKT-01). 
Conflicts of Interest: The authors declare no conflict of interest.

\section{References}

1. Zhao, W.; Zhong, Q.; Pan, Y.; Zhang, R. Systematic effects of S-doping on the activity of $\mathrm{V}_{2} \mathrm{O}_{5} / \mathrm{TiO}_{2}$ catalyst for low-temperature $\mathrm{NH}_{3}$-SCR. Chem. Eng. J. 2013, 228, 815-823. [CrossRef]

2. Qiu, L.; Meng, J.; Pang, D.; Zhang, C.; Ouyang, F. Reaction and Characterization of Co and Ce Doped $\mathrm{Mn} / \mathrm{TiO}_{2}$ Catalysts for Low-Temperature SCR of NO with $\mathrm{NH}_{3}$. Catal. Lett. 2015, 145, 1500-1509. [CrossRef]

3. Thirupathi, B.; Smirniotis, P.G. Nickel-doped $\mathrm{Mn} / \mathrm{TiO}_{2}$ as an efficient catalyst for the low-temperature SCR of $\mathrm{NO}$ with $\mathrm{NH}_{3}$ : Catalytic evaluation and characterizations. J. Catal. 2012, 288, 74-83. [CrossRef]

4. Gao, B.; Xu, T.; Lin, J.; Zhang, L.; Su, E.; Jiang, Z.; Wei, D. Improving the catalytic activity of lipase LipK107 from Proteus sp. by site-directed mutagenesis in the lid domain based on computer simulation. J. Mol. Catal. B Enzym. 2011, 68, 286-291. [CrossRef]

5. Parkhomchuk, E.V.; Vanina, M.P.; Preis, S. The activation of heterogeneous Fenton-type catalyst Fe-MFI. Catal. Commun. 2008, 9, 381-385. [CrossRef]

6. Li, T.; Liu, H.; Fan, Y.; Yuan, P.; Shi, G.; Bi, X.T.; Bao, X. Synthesis of zeolite Y from natural aluminosilicate minerals for fluid catalytic cracking application. Green Chem. 2012, 14, 3255-3259. [CrossRef]

7. Cheng, K.; Liu, J.; Zhang, T.; Li, J.; Zhao, Z.; Wei, Y.; Jiang, G.; Duan, A. Effect of Ce doping of TiO 2 support on $\mathrm{NH}_{3}$-SCR activity over $\mathrm{V}_{2} \mathrm{O}_{5}-\mathrm{WO}_{3} / \mathrm{CeO}_{2}-\mathrm{TiO}_{2}$ catalyst. J. Environ. Sci. 2014, 26, 2106-2113. [CrossRef] [PubMed]

8. Lisovskii, A.F. Thermodynamics of the migration of a liquid phase in a three-phase dispersed system with one dissolving solid phase. J. Superhard Mater. 2008, 30, 101-104. [CrossRef]

9. Liu, Z.; Zhu, J.; Zhang, S.; Ma, L.; Woo, S.I. Selective catalytic reduction of $\mathrm{NO}_{X}$ by $\mathrm{NH}_{3}$ over $\mathrm{MoO}_{3}$-promoted $\mathrm{CeO}_{2} / \mathrm{TiO}_{2}$ catalyst. Catal. Commun. 2014, 46, 90-93. [CrossRef]

10. Liu, F.; He, H.; Zhang, C.; Shan, W.; Shi, X. Mechanism of the selective catalytic reduction of $\mathrm{NO}_{X} \mathrm{with}^{\mathrm{NH}_{3}}$ over environmental-friendly iron titanate catalyst. Catal. Today 2011, 175, 18-25. [CrossRef]

11. Hao, Z.; Li, Y.; Li, H.; Wei, B.; Liao, X.; Liang, T.; Yu, J. Levels of rare earth elements, heavy metals and uranium in a population living in BaiyunObo, Inner Mongolia, China: A pilot study. Chemosphere 2015, 128, 161-170. [CrossRef] [PubMed]

12. Gao, J.Y.; Wang, Y.X.; Qiu, Y.Z.; Zhang, Q. Origin of the Ore-bearing Dolomite in BaiyunObo Ore Deposit. Acta Sedimentol. Sin. 1999, 17, 675-686.

13. Müller, A.; Pietsch, B.; Faccin, N.; Schierle, J.; Waysek, E.H. Method for the Determination of Lycopene in Supplements and Raw Material by Reversed-Phase Liquid Chromatography: Single-Laboratory Validation. J. Aoac Int. 2008, 91, 1284-1297.

14. Godinho, J.R.A.; Piazolo, S.; Evins, L.Z. Effect of surface orientation on dissolution rates and topography of $\mathrm{CaF}_{2}$. Geochim. Et Cosmochim. Acta 2012, 86, 392-403. [CrossRef]

15. Attia, Y.A.; El-Hamid, A.E.A.; Ellakany, H.F.; Bovera, F.; Al-Harthi, M.A.; Ghazaly, S.A. Growing and Laying Performance of Japanese Quail Fed Diet Supplemented with Different Concentrations of Acetic Acid. Ital. J. Anim. Sci. 2013, 12, 381-388. [CrossRef]

16. Yang, F.; Nasr-El-Din, H.; Harbi, B. Acidizing Sandstone Reservoirs Using HF and Organic Acids. In Proceedings of the SPE Production and Operations Symposium, Doha, Qatar, 14-16 May 2012.

17. Ma, Z.; Wu, X.; Si, Z.; Weng, D.; Ma, J.; Xu, T. Impacts of niobia loading on active sites and surface acidity in $\mathrm{NbO}_{X} / \mathrm{CeO}_{2}-\mathrm{ZrO}_{2} \mathrm{NH}_{3}-\mathrm{SCR}$ catalysts. Appl. Catal. B Environ. 2015, 179, 380-394. [CrossRef]

18. Duan, Y.; Wang, J.; Yu, T.; Shen, M.; Wang, J. The role and activity of various adsorbed ammonia species on $\mathrm{Cu} / \mathrm{SAPO}-34$ catalyst during passive-SCR process. Rsc Adv. 2015, 5, 14103-14113. [CrossRef]

19. Zeng, Y.; Wang, Y.; Zhang, S.; Zhong, Q. A study on the $\mathrm{NH}_{3}$-SCR performance and reaction mechanism of a cost-effective and environment-friendly black $\mathrm{TiO}_{2}$ catalyst. Phys. Chem. Chem. Phys. 2018, 20, $22744-22752$. [CrossRef]

20. Watanabe, S.; Ma, X.; Song, C. Characterization of Structural and Surface Properties of Nanocrystalline $\mathrm{TiO}_{2}-\mathrm{CeO}_{2}$ Mixed Oxides by XRD, XPS, TPR, and TPD. J. Phys. Chem. C 2009, 113, 14249-14257. [CrossRef]

21. Ma, C.; Tang, F.; Chen, J.; Ma, R.; Yuan, X.; Wen, Z.; Long, J.; Li, J.; Du, M.; Zhang, J.; et al. Spectral, energy resolution properties and green-yellow LEDs applications of transparent $\mathrm{Ce}^{3+}: \mathrm{Lu}_{3} \mathrm{Al}_{5} \mathrm{O}_{12}$ ceramics. J. Eur. Ceram. Soc. 2016, 36, 4205-4213. [CrossRef] 
22. Paparazzo, E. On the curve-fitting of XPS Ce(3d) spectra of cerium oxides. Mater. Res. Bull. 2011, 46, 323-326. [CrossRef]

23. Yamashita, T.; Hayes, P. Analysis of XPS spectra of $\mathrm{Fe}^{2+}$ and $\mathrm{Fe}^{3+}$ ions in oxide materials. Appl. Surf. Sci. 2008, 254, 2441-2449. [CrossRef]

24. Nesbitt, H.W.; Scaini, M.; Hochst, H.; Bancroft, G.M.; Schaufuss, A.G.; Szargan, R. Synchrotron XPS evidence for $\mathrm{Fe}^{2+}-\mathrm{S}$ and $\mathrm{Fe}^{3+}-\mathrm{S}$ surface species on pyrite fracture-surfaces, and their 3D electronic states. Am. Mineral. 2000, 85, 850-857. [CrossRef]

25. Grossale, A.; Nova, I.; Tronconi, E.; Chatterjee, D.; Weibel, M. The chemistry of the NO/NO${ }_{2}-\mathrm{NH}_{3}$ "fast" SCR reaction over Fe-ZSM5 investigated by transient reaction analysis. J. Catal. 2008, 256, 312-322. [CrossRef]

26. Shen, B.X.; Liu, T. Deactivation of $\mathrm{MnO}_{X}-\mathrm{CeO} / \mathrm{ACF}$ Catalysts for Low-Temperature $\mathrm{NH}_{3}-\mathrm{SCR}$ in the Presence of $\mathrm{SO}_{2}$. Acta Phys. Chim. Sin. 2010, 26, 3009-3016.

27. Ling, Q.; Yang, M.; Li, C.; Zhang, A. Preparation of Monolayered Ce-Fe Oxides Dispersed on Graphene and Their Superior Adsorptive Behavior. Fuller. Nanotub. Carbon Nanostruct. 2015, 23, 158-164. [CrossRef]

(C) 2020 by the authors. Licensee MDPI, Basel, Switzerland. This article is an open access article distributed under the terms and conditions of the Creative Commons Attribution (CC BY) license (http://creativecommons.org/licenses/by/4.0/). 